\title{
The Plain Truth about Plain Packaging: An Econometric Analysis of the Australian 2011 Tobacco Plain Packaging Act
}

\author{
Sinclair Davidson ${ }^{1}$ and Ashton de Silva ${ }^{2}$
}

\section{Abstract}

From December 2012 standardised packaging for tobacco products - known as 'plain packaging' - has been mandatory in Australia. This paper evaluates the preliminary evidence - in the form of ABS household expenditure on tobacco datato establish whether the policy has been successful. Despite our econometric efforts, the data refused to yield any indication this policy has been successful; there is no empirical evidence to support the notion that the plain packaging policy has resulted in lower household expenditure on tobacco than there otherwise would have been. There is some faint evidence to suggest, ceteris paribus, household expenditure on tobacco increased.

\section{Introduction}

Since December 2012 all cigarettes (legally) sold in Australia have been required to be packaged in a standardised package. In Australia this is known as the 'plain packaging' policy. Australia is the first country to introduce standardised cigarette packaging and media reports suggest that similar policies are being considered in, at least, Ireland, New Zealand and the United Kingdom.

In mid-2014 a media debate erupted as to the efficacy of the plain packaging policy (see, for example, Kerr 2014; Kerr and Creighton 2014; Smyth 2014a, b). Tobacco industry sources suggested that tobacco consumption had increased following the introduction of plain packaging (Kerr 2014). Anti-tobacco activists pointed to Australian Bureau of Statistics (ABS) (2014a) data indicating that while household expenditure on tobacco products had increased over 2013, it

RMIT University and Institute of Public Affairs, sinclair.davidson@rmit.edu.au.

RMIT University, ashton.desilva@rmit.edu.au. 
had dramatically fallen in the first quarter of 2014. Those activists interpreted that massive 2014 first-quarter decline as evidence the plain package policy had worked (Smyth 2014a, b).

The difficulty arises in that those two observations may well be consistent with each other. The difference between consumption and expenditure is, of course, price. To most laypeople, however, consumption of tobacco and expenditure on tobacco appear equivalent. Economists know better - consumption is a quantity measure, while expenditure is price times quantity. Journalists, however, seem to not always understand the distinction; Smyth $(2014 a, b)$, for example, refers to the ABS as reporting tobacco consumption falling in his Financial Times articles. The ABS, of course, reported no such thing - it reported Household Tobacco expenditure falling.

A further difficulty arises in that the ABS reports 'real' (chain volume) statistics for household expenditure that attempt to abstract from changes in prices. In practice, however, the ABS does not hold price constant, as many appear to imagine. Were that the case it would be easy to infer trends in consumption from trends in expenditure. To the extent that consumers face falling prices for tobacco products or consumers substitute cheaper brands of tobacco products for more expensive brands the relationship between quantity consumed and expenditure becomes indeterminate. (See Appendix 1 for a worked example on these points.)

Further clouding some commentators' appreciation of the situation, the 2013 National Drug Strategy Household Survey results (Australian Institute of Health and Welfare 2014) indicated that overall tobacco consumption was down on 2010 data - but that cannot establish any efficacy of the plain packaging policy per se in addition to the long-term downward trend in tobacco consumption.

Whatever the right answer to the question, the merit of the plain packaging policy clearly extends beyond the health-tobacco nexus. Tobacco companies, unable to deploy their intellectual property in promoting their products, have pursued legal action against Australia at the World Trade Organisation. Public health advocates would want to have an understanding of the impact plain packaging has on tobacco consumption before advocating similar policies for other 'repugnant goods' such as alcohol or fast food or high-salt or high-sugar content foods.

In this paper we present some very preliminary evidence to show that there is no empirical support for the plain packaging policy. Like the anti-tobacco lobby, we employ ABS household expenditure of tobacco data. The advantages to using this measure are that it is publicly available and not proprietary to the tobacco industry. There are limitations to using expenditure data as a proxy for 
consumption data - as we have outlined above; unfortunately, however, actual tobacco consumption data are not publicly available for analysis. Even if readers are uncomfortable accepting expenditure data as being a proxy for consumption, our results show that the first-quarter decline in household expenditure on tobacco is not explained by the introduction of the plain packaging policy.

In section 2 we set out some of the theoretical considerations that inform our problem. Section 3 contains some discussion of an ideal test and real-world limitations to conducting an ideal test. Section 4 contains our empirical tests and a conclusion follows.

\section{Theoretical predictions}

There are two questions of principle worth exploring. First, what would the impact of imposing plain packaging (i.e. removing the scope for non-price competition through branding) have on the pricing of tobacco products such as cigarettes? Second, what impact would the plain packaging policy have on the demand for cigarettes at a given price?

Cigarettes are more or less homogeneous products - medical researchers report that smokers are unable to differentiate different brands of cigarette (Campbell 2012). Branding and product differentiation allow firms to maintain consumer loyalty and/or charge price premia for their goods and services. Over the last 30 years, however, there have been ever-increasingly stringent regulations against tobacco advertising. The plain packaging policy is the logical conclusion of that regulatory push - there is now no means whereby tobacco companies can maintain consumer loyalty. Tobacco firms can now only compete on price. In the absence of non-price competition, and the presence of (more or less) perfect substitutability, the Bertrand equilibrium price now equals marginal cost, possibly resulting in an increase in consumption.

On that basis, the first implication of a plain packaging policy, ceteris paribus, would be that tobacco prices can be expected to fall. Related to this is the prediction that consumers will substitute away from high-priced cigarettes to lower-priced cigarettes.

The definitive source guide to tobacco data (Scollo and Winstanley 2012) has dated data but they (2012, section 13.3.2.2) report that price discounting is common in Australia - that 'the majority of cigarettes in Australia are sold at considerably lower prices' than the recommended retail price. They also report (2012, section 13.3.1.1) that the recommended retail price of their chosen representative packet of cigarettes (Craven A) had fallen in price in 2012 to $\$ 10.36$ from $\$ 15.52$ the previous year. Unfortunately, they do not report prices 
for that brand in 2013. The ABS (2014b) reports, however, that the tobacco CPI has continued to rapidly increase and the growth in tobacco prices has outstripped overall CPI. At the same time there is evidence to suggest that tobacco consumers are substituting to cheaper brands of cigarette. Kerr and Creighton (2014) report that the 'deep discount' segment of the tobacco market has grown to a 28.2 per cent market share in 2014 from 3.4 per cent in 2010 .

To the extent that branding disappears it also becomes easier for counterfeit or illegal tobacco to enter the Australian market. Ironically, the governmentmandated standardised packs are themselves not trademarked and criminals can easily reproduce them. The second implication of the plain packaging policy, ceteris paribus, is that the market share of illegal tobacco will increase (Farrell and Fry 2013). Clarke and Prentice (2012) provide an analysis of both these claims and suggest that, at best, they are overstated. But what is important for our purposes is that Clarke and Prentice (2012) agree that a plain packaging policy could cause prices to fall and consumption to rise, and they recommend that increases in excise tax be employed to prevent tobacco prices from falling. By contrast, Farrell and Fry (2013) suggest that plain packaging would blur the distinction between legal and illegal tobacco and result in a greater demand for illegal tobacco. They suggest that this could result in perverse health outcomes given the objective of reducing tobacco consumption. A problem shared by both of these papers is that they both pre-date the introduction of the plain packaging policy. The Farrell and Fry paper, even though published in 2013, uses data from the late 2000s.

The second question relates to the demand for tobacco at any given price level after the introduction of plain packaging. The medical literature suggests that plain packaging reduces the utility of the smoking experience. Germain, Wakefield and Durkin (2010), for example, find that plain packaging reduces positive brand-image associations for adolescents, and raises negative expectations as to taste. Similarly, Wakefield et al. (2013) find that plain packaging reduces the perceived quality of tobacco products, and that consumers perceive plainpackaged tobacco products to be less satisfying than branded tobacco. Young et al. (2014) report an increase in the number of phone calls to Quitline - a helpline for smokers - after the introduction of the plain packaging policy, but do not indicate actual quit rates.

The difficulty with all these studies is that they do not demonstrate that tobacco consumers will actually stop smoking - rather that one aspect of the utility of the smoking experience has been lost. If smokers gain utility from both consuming a branded tobacco product and from the tobacco itself (nicotine, for example) then it may easily be the case that restricting branding could give rise to an increase in tobacco consumption as smokers attempt to maintain their overall smoking experience (see Lancaster 1966, 1975). Ironically some 
smokers could find themselves consuming more tobacco while enjoying less of the smoking experience. The observation that consumers of low-tar (or socalled light cigarettes) tend to inhale more deeply or more frequently would be consistent with this argument (see Benowitz et al. 1983).

In short, from an a priori economic perspective it is possible that plain packaging could lead to increased tobacco consumption. By contrast, the public health literature suggests that plain packaging will result in reduced consumption by discouraging younger individuals from taking up tobacco consumption and by amplifying the message in the health warnings.

\section{An ideal test and real-world limitations}

Ideally, the impact of the policy change would be tested by examining the change in tobacco consumption, controlling for changes in price, income, population, etc. The challenge, however, is that 'tobacco sales data are not publicly available' (Department of Health 2014).

To date, the 'success' of the plain packaging policy has rested on very imperfect indicators - for example, the number of individuals calling Quit services and the like. There is, however, at present no definitive evidence to support the efficacy of the plain packaging policy. By contrast Kaul and Wolf (2014) are able to employ (proprietary) smoking data from Roy Morgan and show that the plain packaging policy had no impact on the incidence of 14-17-year-old tobacco consumers. $^{3}$

In fact, the evidence to support the efficacy of most tobacco regulation in Australia is somewhat weak. Under Freedom of Information laws, Treasury (undated) has released some modelling of tobacco demand where tobacco excise data are used to proxy tobacco consumption. Unfortunately, those data are also not in the public domain. Nonetheless they employ OLS to estimate price and income elasticities for tobacco and include a regulation variable in their analysis. Unfortunately, the (undated) Treasury paper is insufficiently detailed to reveal the time period or specific regulations under consideration, but the Regulation variable in the analysis is not statistically significantly different from zero at the 5 per cent significance level.

Data limitations represent the clearest challenge to establishing the efficacy of the plain packaging policy and, indeed, most tobacco regulation. Ideally, total

3 They fit a linear time trend to the consumption data and test for statistically significant deviations from the trend after the introduction of the plain packaging policy. 
consumption, or per capita consumption, of tobacco would feature prominently in that analysis. For obvious reasons, however, standardised time-series data for illegal tobacco consumption is non-existent.

Excise data is collected on a per-stick basis (or per-stick equivalent basis) but that data is not publicly available. Similarly, tobacco firms have detailed information of their sales but those data are also not publicly available either. The National Drug Strategy Household Survey collects data on the incidence of tobacco consumption, but only on a three-year cycle.

At present the 'best' tobacco data are the Household Expenditure on Tobacco data produced by the ABS. These data, however, are a very imperfect proxy for tobacco consumption. The data series is from September 1959 to March 2014 (at the time of writing). It peaks in 1981 and since that time household expenditure of tobacco has declined. By contrast, Scollo and Winstanley (2012, section 2.10.1) report that tobacco consumption has been in long-term decline in Australia since 1960. They also report (2012, section 2.6.2) a comparison between known tobacco datasets and show that the ABS data under-report tobacco consumption relative to both industry estimates and Treasury estimates of tobacco consumption.

\section{Three imperfect tests}

In this section results from three tests are presented, the first of which is based on the regression approach using the ordinary least squares (OLS) methodology, similar to that used in Treasury (undated). Recognising that OLS at times does not handle economic time-series very well due to its stochastic properties, we subsequently employ a univariate form of the state space specification recently used in Davidson and de Silva (2013). In the third test we perform a historic forecasting scenario.

In all three empirical tests the ABS Household Expenditure data are used as a proxy for tobacco consumption.

\section{Test 1: Regression}

The regression analysis follows the format:

Expenditure $_{t}=\alpha_{0}+\beta_{1}$ Price $_{t}+\beta_{2}$ Income $_{t}+\beta_{3}$ Regulation Dummy $_{t}+\varepsilon_{t}$ where: 
Expenditure $_{t}=$ seasonally adjusted household tobacco expenditure (sourced from the ABS 2014a, table 8; this is a chain volume measure - see ABS 2013 for an explanation) divided by the estimated resident Australian population (also sourced from the ABS 2014c $\mathrm{c}^{4}$ )

Price $_{t}=$ A tobacco price proxy; following Treasury (undated) we employ the ABS (2014b) CPI tobacco sub-index as the proxy for tobacco prices ${ }^{5}$

Income $_{\mathrm{t}}=$ seasonally adjusted gross disposable household income (sourced from the ABS 2014a, table 14 - these data are in current dollars ${ }^{6}$ ) divided by the estimated resident Australian population (also sourced from the ABS 2014c)

Regulation Dummy $=$ a series of binary variables designed to capture major regulatory change, Excise 1 captures the 25 per cent excise increase in April 2010, Excise 2 captures the 12.5 per cent increase in excise in December 2013 and Plain Packaging captures the introduction of plain packaging in December 2012. On the advice of the referee we also investigated whether the introduction of plain packaging after September had any impact on household tobacco expenditure. $^{7}$

To avoid complications associated with the introduction of the Goods and Services Tax in 2000, we estimate the model over the period 2001-14.

The data captured from the ABS are all quarterly data - ideally we would employ higher-frequency data, but unfortunately the ABS only reports national income data and CPI data on a quarterly basis. A referee has suggested that the use of resident Australian population is an inappropriate denominator for Expenditure and Income in our regression models, indicating that the number of households would be a more appropriate measure. Unfortunately, a high-frequency time series of the number of Australian households is not available for use. The Australian Institute of Family Studies, however, does provide an estimate of the average household size in Australia for the period 1911-2011. Using those data and the estimate of resident population, it is possible to estimate the number of households in Australia. The estimate for average household size over our estimation period, however, is a constant 2.6 persons per household. As such, we report results using population as the denominator.

\footnotetext{
4 The ABS population data are current to December 2013. To estimate the March 2014 population data we average the population estimate in the ABS population clock in June 2014 and December 2013.

5 Although elsewhere in Treasury (undated) they report results for a proxy using price per stick.

6 In unreported analysis we use the overall CPI to adjust the current dollars into real 2014 dollars and re-run our regressions - the results are marginally different but qualitatively identical.

7 After 1 December 2012 all packs sold were required to be in plain packaging but plain packaged cigarettes were already on the market. After September 2012 all manufacturers were required to produce cigarettes in plain packaging and these packs became available for sale alongside branded packs.
} 
The initial estimation of the model indicated a high level of auto-correlation and consequently an AR(1) term was added to the model. Initially we also included a time trend; however, the results indicated the time trend was redundant and it was excluded from the final analysis (results available upon request). Different versions of equation (1) were estimated. Results of the regression analysis are shown in Table 1 (with Newey-West p-values shown in parenthesis).

Table 1: Regression results

\begin{tabular}{lrrrr}
\hline & \multicolumn{1}{l}{$\mathbf{1}$} & \multicolumn{1}{l}{3} & \multicolumn{1}{l}{$\mathbf{4}$} \\
\hline C & 7.8663 & 7.6019 & 7.9542 & 7.7002 \\
& $(0.0000)$ & $(0.0000)$ & $(0.0000)$ & $(0.0000)$ \\
Price & -0.7028 & -0.8067 & -0.6548 & -0.7598 \\
& $(0.0000)$ & $(0.0000)$ & $(0.0000)$ & $(0.0000)$ \\
Income & 0.0413 & 0.1187 & 0.0093 & 0.0861 \\
& $(0.5739)$ & $(0.0845)$ & $(0.9091)$ & $(0.0000)$ \\
Excise 1 & 0.0801 & 0.0976 & 0.0728 & 0.0898 \\
& $(0.0002)$ & $(0.0000)$ & $(0.0012)$ & $(0.0000)$ \\
Excise 2 & -0.0324 & & -0.0348 & \\
& $(0.0052)$ & & $(0.0080)$ & \\
Plain Packaging & 0.0186 & 0.0229 & 0.0052 & 0.0085 \\
& $(0.1582)$ & $(0.0757)$ & $(0.6540)$ & $(0.0000)$ \\
AR(1) & 0.7101 & 0.6596 & 0.7302 & 0.6794 \\
& $(0.0000)$ & $(0.0000)$ & $(0.0000)$ & $(0.0000)$ \\
Adj-R2 & 0.9889 & 0.9884 & 0.9886 & 0.9880 \\
DW & 1.8843 & 1.8547 & 1.8789 & 1.8159 \\
\hline
\end{tabular}

Source: Authors' analysis.

Columns 1 and 2 report regression results where the Plain Packaging dummy relates to the December 2012 introduction of the plain packaging policy, while columns 3 and 4 report results for an effective September 2012 introduction of plain packaging. Overall, the models appear to be well-specified, and the coefficients on Price are negative and statistically significantly different from zero. ${ }^{8}$ In columns 1 and 3 we have estimated the complete model. In columns 2 and 4 we have excluded Excise 2 from the analysis. This is to examine the impact of the plain packaging policy while not controlling for the 2013 increase in excise.

8 If the semi-elasticity of expenditure to price is negative, then the elasticity of quantity to price is certainly negative. Notice also that the positive sign on the Excise 1 coefficients is not hard to rationalise. Recall we are modelling expenditure data and not quantity demanded. As prices rise due to excise increases so expenditure rises too. We also observe over time that excise revenue to the budget has increased with increased excise. 
The variable of interest for our purposes is the coefficient for Plain Packaging. In no instance is the coefficient negative and statistically significantly different from zero. In that sense we can argue that the plain packaging policy has not made any contribution to the long-term decline in household tobacco expenditure (our very imperfect proxy for consumption). By contrast, however, there are two instances (columns 2 and 4) where the Plain Packaging coefficient is positive and statistically significantly different from zero $(p=0.0757$ and $p=0.0000)$. That result is consistent with the predictions from economic theory that suggest ceteris paribus that the absence of branding would result in an increase in the consumption of tobacco. It is important to note that in columns 2 and 4 we are not controlling for the 2013 excise. The difficulty that we face is that there is only a single data point for Excise 2 and it corresponds to a large decline in household expenditure on tobacco - future work will be needed to unravel the interaction between the plain packaging policy and the excise increase.

Overall, however, the regression result should be treated with some caution. The policy effect we are examining occurs at the end of the period, and the data themselves are subject to ongoing revision. As it stands, however, there is no evidence to support the efficacy of the plain packaging policy.

\section{Test 2: Univariate state space model}

In this section results from a method similar to that used in Davidson and de Silva (2013) are presented. Specifically we test, after accounting for historically defined patterns in the latent components, ${ }^{9}$ whether there is any evidence that household expenditure on tobacco has deviated from the norm following the introduction of the plain packaging legislation?

The econometric technique we employ is also commonly referred to as an unobservable-components model (Harvey 1989). ${ }^{10}$ Many economic studies have utilised this approach to assess economic policy and concepts (see, Harvey and Durbin 1986; Tawados 2009; and Sinclair et al. 2012, for example).

If we let $y_{\mathrm{t}}$ denote an observation at time $t$, the formulation can be represented as follows:

$$
\begin{aligned}
& y_{t}=H x_{t}+\varepsilon_{t^{\prime}} \\
& x_{t}=F x_{t-1}+v_{t^{\prime}}
\end{aligned}
$$

9 Latent components are the estimated stylised features (i.e. the trend and seasonality) that combine to form the observations. In this instance we apply an approach that disaggregates expenditures into their trend and seasonal parts. In contrast to a traditional OLS regression technique, it can capture changes in these features over time.

10 The model is fitted using the computer package STAMP 8.2 (Koopman et al. 2009). 
where (2.2) captures how the observations evolve over time according to the latent components of the variable of interest. Two types of latent components are considered in our analysis, they being a trend and seasonality. These components are captured in the vector $x_{t}$. How these components evolve over time and combine to measure the observation $\left.y_{t}\right)$ is (pre)determined by the values in $H$ and $F$. The first and second equations are typically referred to as the observation and state equations respectively. Commonly the errors in the equations are assumed to be a normal with a mean of zero and a fixed variance.

The motivation for using this approach in this context is similar to Davidson and de Silva (2013), namely:

1. It provides the means of modelling the series consistent with the spirit of the Sims (1980) approach; that is, we do not need to impose any prior theoretical restrictions on the model thus letting the data speak.

2. The variables can be modelled 'as is'; that is, we do not need to perform transformations such as differencing that will necessarily result in changes in interpretation.

3. The model captures stochastic time-series characteristics, and thus is flexible enough to account for any variation in the latent components, such seasonal factors, over time. (Consequently in this section we employ original ABS (2014a) data and not the seasonally adjusted data we employed in the previous section.)

In testing whether consumption has deviated from the norm, a two-step procedure is undertaken. In the first instance an automated algorithm in STAMP was used to detect whether there were any structural changes (breaks) in the time path of expenditure. ${ }^{11}$ As there was no evidence of any breaks corresponding to the introduction of the plain packaging legislation we then manually tested for a break, taking account of the automatically determined breaks previously found. ${ }^{12}$ Table 2 presents the key results. Each row represents a structural change in the time path of the series. For example, a negative one-off impact seems to have occurred in 2000(3); similarly a downward shift in the underlying average in the last quarters of 1976 and 1978 seems to have occurred.

11 The automatic routine is based on Harvey and Koopman (1992).

12 Impulse breaks were also formally tested for each quarter 2012-2013. No evidence of an impulse break was found. Unfortunately, due to the first quarter of 2014 being the most recent observation we were not able to formally evaluate whether it represents a statistically significant decrease. 
Table 2: Break coefficients

\begin{tabular}{lll}
\hline Break Type & Coefficient & P-value \\
\hline Outlier 1973(3) & 338.183 & $(0.0003)$ \\
Outlier 1975(2) & 325.659 & $(0.0004)$ \\
Outlier 1977(3) & -318.800 & $(0.0007)$ \\
Outlier 1981(4) & 276.134 & $(0.0027)$ \\
Outlier 2000(3) & -377.562 & $(0.0001)$ \\
Level break 1976(4) & 546.599 & $(0.0000)$ \\
Level break 1978(4) & -333.916 & $(0.0033)$ \\
Level break 1983(2) & -497.250 & $(0.0000)$ \\
Level break 2013(1) & 90.218 & $(0.4325)$ \\
\hline
\end{tabular}

Note: One-off impacts denoted as outliers, level breaks represent a change in the underlying average. All breaks except the 2013(1) were automatically detected.

Source: Authors' analysis.

In conclusion, we have specifically tested for evidence of a deviation in expenditure from a norm defined by latent components typically found in economic data following the introduction of plain packaging. The result is that the hypothesis of a change is rejected $(p=0.4325)$. That is, there is no evidence to suggest household expenditure on tobacco has changed.

\section{Test 3: A historically based forecasting scenario}

In the third approach we apply an automated forecasting method that has been proven to have been successful on a vast array of time-series data. The method is based on a univariate single source of error state space model that captures 30 different specifications (Hyndman et al. 2008). The approach is fully automated and extremely flexible in that it is able to model various forms of time-series characteristics (Hyndman et al. 2002). Assuming, as before, that $y(t)$ denotes expenditure at time ' $\mathrm{t}$ ', the approach has a general form of:

$$
\begin{aligned}
& \mathrm{Y}(\mathrm{t})=\mathrm{h}(\mathrm{x}(\mathrm{t}-1))+\mathrm{k}(\mathrm{x}(\mathrm{t}-1)) \mathrm{e}(\mathrm{t}) \\
& \mathrm{X}(\mathrm{t})=\mathrm{F}(\mathrm{x}(\mathrm{t}-1))+\mathrm{g}(\mathrm{x}(\mathrm{t}-1)) \mathrm{e}(\mathrm{t})
\end{aligned}
$$

Though the specification is similar to the one used in test 2, it has been shown to be more general in nature (Hyndman et al. 2008) and therefore provides a natural alternative to the model considered in the previous approach given the design of this test.

In this approach we essentially ask: what if the plain packing legislation had not been introduced? Noting that the legislation became effective in December 2012, 
we perform a forecasting exercise using the data available from 1959 to 2012 . By comparing the actuals in policy period to the prediction intervals we can then determine whether, based on historical patterns, consumption has deviated from the expected path.

In Figure 1 the actual household expenditure on tobacco is contrasted with 80 per cent and 95 per cent prediction intervals. The solid line (actual data) is clearly above the lower 80 per cent bound, indicating that spending was not abnormally low in 2013. Interestingly, the actuals appears to be mapping directly onto the corresponding 80 per cent upper bound, suggesting, prima facie, that expenditure was high relative to historical expenditure levels. Given the actuals are within the 95 per cent prediction intervals, we conclude that there is no evidence that plain packaging has changed spending levels in this expenditure category.

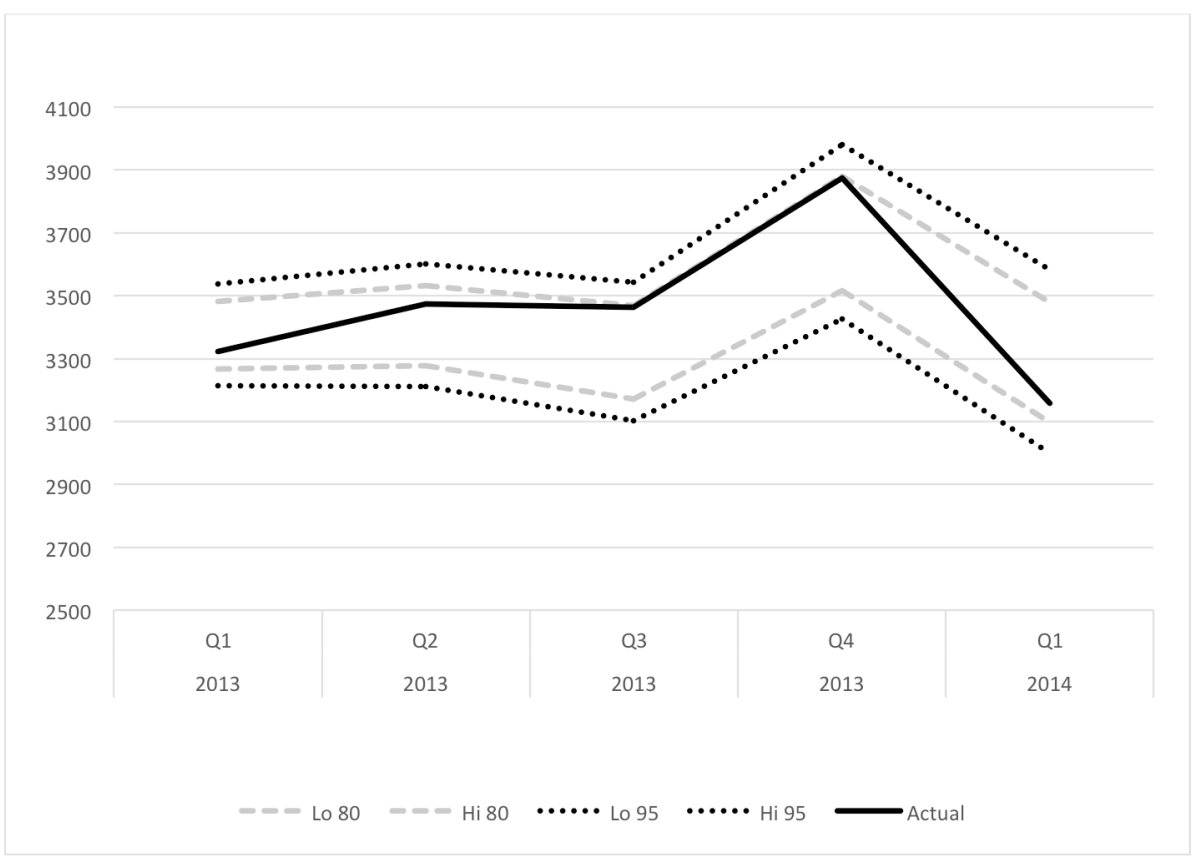

\section{Figure 1: Actual tobacco expenditure and forecast prediction intervals}

Source: Authors' calculations.

In conclusion, consistent with the other test results, the results suggest there is no evidence that household expenditure on tobacco has changed following the introduction of the plain packaging legislation. 


\section{Conclusion}

Ronald Coase famously argued that if you tortured the data long enough they would confess. In this paper we have tortured the data, but there has been no confession. At best, we can determine the plain packaging policy introduced in December 2012 has not reduced household expenditure of tobacco once we control for price effects, or the long-term decline of tobacco expenditure, or even the latent attributes of the data.

To the contrary, we are able to find a suggestion that household expenditure of tobacco has, ceteris paribus, increased. In our forecasting exercise the actual data come close to breaking through the 80 per cent confidence interval. While we do not want to over-emphasise these results, we do conclude that any evidence to suggest that the plain packaging policy has reduced household expenditure on tobacco is simply lacking.

There are two very important caveats to our results. In the first instance, data on actual (legal) tobacco consumption (on a per-stick basis) do exist, though not in the public domain. Publicly available data on household tobacco expenditure are an imperfect proxy for tobacco consumption - as the 'Tobacco in Australia' report concedes. In any event, the ABS data are potentially subject to substantial revision and cannot answer well the questions being asked of them.

Establishing the efficacy of the plain packaging policy will take painstaking econometric analysis over a long period of time. This will involve having to untangle the effects of excise increases and changes in smoker behaviour, and substitution to illegal tobacco products. As things stand at the minute, it would be a very brave public-health advocate that claims vindication from one data point (subject to revision) in supporting the plain packaging policy.

\section{Appendix 1}

This appendix presents a hypothetical counter-example to the contention that chain volume measures of expenditure always accurately capture movements in quantity of cigarettes consumed. The example assumes that the total quantity of cigarettes remains at 100, but it shows that chain volume will be measured as falling.

The ABS reports household expenditure data in real terms - specifically they employ chain-volume measures. ABS (2014a) provides a detailed explanation 
of its approach and ABS (2003) provides a worked example of how to calculate chain volume data. In this appendix we offer a slightly more complex example than the ABS presents.

First, we assume four brands of cigarette; Premium, Mid-Price, Low-Price, and Deep Discount. We also assume in each year that 100 cigarettes are consumed. We use market share data (from Kerr and Creighton 2014) to allocate those 100 cigarettes to each brand over four years. We then assume prices for each brand in the first year $(\$ 20, \$ 15, \$ 12, \$ 10)$ - we have no knowledge if these prices are 'realistic' or not. Scollo and Winstanley (2012, section 13.3) provide a time series of prices for the 'Craven $\mathrm{A}^{\prime}$ brand of cigarettes. They report a price of $\$ 12.68$ in 2010, $\$ 15.52$ in 2011, but only $\$ 10.36$ in 2012. Unfortunately, they do not report a 2013 price. In this example, we wish to demonstrate a point, not provide a realistic or detailed explanation of the actual ABS data. We then increase prices in each period by $\$ 2$ for each brand of cigarette.

Table Al sets out the details. We then calculate an Index Value for each year, where

Index Value $=\frac{\sum P 1 Q 2}{\sum P 1 Q 1} \times \frac{\sum P 2 Q 3}{\sum P 2 Q 2} \times \ldots \frac{\sum P n-1 Q n}{\sum P n-1 Q n-1}$

The Index Value becomes an index number simply by multiplying by 100 . The Index Value can be expressed in dollar terms by multiplying it by the Total Expenditure figure in the reference year - in our case, year 1. These calculations are performed and shown in Table A.1.

The effect of our assumptions is that overall quantity of tobacco consumption is constant, but the composition of the consumption changes. Smokers are substituting from higher-priced brands to lower-priced brands. Each year, the price of cigarettes is rising and Total Household Expenditure is rising. That, however, is not reflected in the Chain Volume measure that attempts to strip out price effects. What is happening there is that the lower-priced brands are being more heavily weighted in the calculation by lagged prices (which are themselves lower than the current period prices). While controlling for increased prices in each period, the calculation does not adequately control for substitution effects and so the reported household expenditure in chain-volume terms falls, even as actual household expenditure in current terms is rising.

It is also possible to generate numbers that show chain-volume expenditure falling while quantity consumed increases. Such an outcome would reconcile the observations of both the tobacco industry and anti-tobacco lobbyists. 
Table A1: Stylised example of household expenditure on tobacco

\begin{tabular}{|c|c|c|c|c|c|c|c|c|c|c|c|c|c|c|c|}
\hline & 1 & & & 2 & & & 3 & & & 4 & & & 5 & & \\
\hline & P1 & Q1 & P101 & P2 & 02 & P2O2 & P3 & 03 & P303 & P4 & Q4 & P404 & P5 & Q5 & P505 \\
\hline Premium & 20 & 19.3 & 386 & 22 & 18.4 & 404.8 & 24 & 17.5 & 420 & 26 & 15.8 & 410.8 & 28 & 13.6 & 380.8 \\
\hline Mid Price & 15 & 54.7 & 820.5 & 17 & 52.7 & 895.9 & 19 & 50.9 & 967.1 & 21 & 46.8 & 982.8 & 23 & 41.9 & 963.7 \\
\hline Low Price & 12 & 22.6 & 271.2 & 14 & 22.6 & 316.4 & 16 & 21.3 & 340.8 & 18 & 17.7 & 318.6 & 20 & 16.3 & 326 \\
\hline $\begin{array}{l}\text { Deep } \\
\text { Discount }\end{array}$ & 10 & 3.4 & 34 & 12 & 6.3 & 75.6 & 14 & 10.4 & 145.6 & 16 & 19.6 & 313.6 & 18 & 28.2 & 507.6 \\
\hline $\begin{array}{l}\text { Total } \\
\text { Expenditure }\end{array}$ & & 100 & 1512 & & 100 & 1693 & & 100 & 1874 & & 100 & 2026 & & 100 & 2178 \\
\hline $\begin{array}{l}\text { Index } \\
\text { Number }\end{array}$ & & 100 & & & 98.7 & & & 97.6 & & & 95.1 & & & 92.9 & \\
\hline $\begin{array}{l}\text { Chain Volume } \\
\text { Estimate }\end{array}$ & & 1512 & & & 1493 & & & 1476 & & & 1438 & & & 1404 & \\
\hline
\end{tabular}

Source: Authors' analysis.

\section{References}

Australian Bureau of Statistics 2003, Demystifying Chain Volume Measures, ABS Cat. 1367.5.

2013, Australian System of National Accounts: Concepts, Sources and Methods, ABS Cat. 5216.0.

— 2014a, Australian National Accounts: National Income, Expenditure and Product, ABS Cat. 5206.0.

2014b, Consumer Price Index, ABS Cat. 6401.0.

— 2014c, Australian Demographic Statistics, ABS Cat. 3101.0.

Australian Institute of Family Studies, undated, 'Family Facts and Figures: Australian households', www.aifs.gov.au/institute/info/charts/ households/\#havsize (accessed: June 2014).

Australian Institute of Health and Welfare, 2014, National Drugs Strategy Household Survey 2013 survey. Available at www.aihw.gov.au/alcohol-andother-drugs/ndshs/

Benowitz, N., Hall, S., Herning, R., Jacob, P. 3rd, Jones, R. and Osman, A. 1983, 'Smokers of low-yield cigarettes do not consume less nicotine', New England Journal of Medicine 309(3): 139-42. 
Campbell, D. 2012, 'Plain packs will make smoking history', The Guardian, 25 January 2012.

Clarke, H. and Prentice, D. 2012, 'Will Plain Packaging Reduce Cigarette Consumption?' Economic Papers 31(3): 303-17.

Davidson, S. and De Silva, A. 2013, 'Stimulating Savings: An Analysis of Cash Handouts in Australia and the United States', Agenda: A Journal of Policy Analysis and Reform 20(2): 39-57.

Department of Health, 2014, Tobacco key facts and figures. www.health.gov.au/ internet/main/publishing.nsf/Content/tobacco-kff

Farrell, L and Fry, T 2013, 'Is Illicit Tobacco Demand Sensitive to Relative Price?' Economic Papers 32(1): 1-9.

Germain, D., Wakefield, M.A. and Durkin, S.J. 2010, 'Adolescents' Perceptions of Cigarette Brand Image: Does Plain Packaging Make a Difference?' Journal of Adolescent Health 46(4): 385-392.

Harvey, A. 1989, Forecasting, Structural Time Series Models and the Kalman Filter, Cambridge: Cambridge University Press.

Harvey, A.C. and Durbin, J. 1986, 'The effects of seat belt legislation on British road casualties: A case study in structural time series modelling', Journal of the Royal Statistical Society Series A (General): 187-227.

Harvey, A.C. and Koopman, S.J. 1992, 'Diagnostic checking of unobservedcomponents time series models', Journal of Business \& Economic Statistics 10(4): 377-89.

Hyndman, R.J., Akram, M. and Archibald, B.C. 2008, 'The admissible parameter space for exponential smoothing models', Annals of the Institute of Statistical Mathematics60(2): 407-26.

Hyndman, R.J., Koehler, A.B., Snyder, R.D. and Grose, S. 2002, 'A state space framework for automatic forecasting using exponential smoothing methods', International Journal of Forecasting 18(3): 439-54.

Hyndman, R.J., Koehler, A.B., Ord, J.K. and Snyder, R.D. 2008, 'Forecasting with exponential smoothing: the state space approach', Springer-Verlag. www.exponentialsmoothing.net

Kaul, A. and Wolf, M. 2014, 'The (Possible) Effect of Plain Packaging on the Smoking Prevalence of Minors in Australia: A Trend Analysis', University of Zurich Department of Economics Working Paper Series, No. 149. Available at: www.econ.uzh.ch/static/workingpapers.php?id=828 
Kerr, C. 2014, 'Labor's plain packaging fails as cigarette sales rise', The Australian, 6 June 2014.

Kerr, C. and Creighton, A. 2014, 'Plain wrong? Here are the facts: cheap smokes are on the rise since plain packaging', The Australian, 18 June 2014.

Koopman, S., Harvey, A., Doornik, J. and Shephard, N. 2009, Structural Time Series Analyser, Modeller and Predictor (STAMP 8.2) Timberlake Consultants.

Lancaster, K. 1966, 'A new approach to consumer theory', Journal of Political Economy 74: 132-57.

— 1975, 'Socially Optimal Product Differentiation', American Economic Review 65(4): 567-85.

Scollo, M.M. and Winstanley, M.H. 2012, Tobacco in Australia: Facts and issues, 4th edn. Melbourne: Cancer Council Victoria. Available from www. TobaccoInAustralia.org.au

Sinclair, S., Boymal, J. and de Silva, A. 2012, 'A Re-appraisal of the Fertility Response to the Australian Baby Bonus', Economic Record 80(1): 78-87.

Smyth, J. 2014a, 'Australians stub out cigarettes in wake of plain-pack law', Financial Times, 11 June 2014.

_ 2014b, 'Australia smoking rates tumble after plain packaging shift', Financial Times, 17 July 2014.

Tawadros, G.B. 2009, 'Testing the impact of inflation targeting on inflation', Journal of Economic Studies 36(4): 326-42.

Treasury, Undated, Issues in Tobacco Taxation, Available at: www.treasury. gov.au/ /media/Treasury/Access $\% 20$ to \%20Information/Disclosure $\% 20$ Log/2011/Plain\%20packaging\%20of\%20tobacco\%20products/Downloads/ Document_57.ashx

Wakefield, M.A., Hayes, L., Durkin, S. and Borland, R. 2013, 'Introduction Effects of the Australian Plain Packaging Policy on Adult Smokers: A CrossSectional Study, BMJ Open 3(7): http://bmjopen.bmj.com/content/3/7/ e003175.full

Young, J., Stacey, I., Dobbins, T., Dunlop, S., Dessaix, A. and Currow, D. 2014, 'Association between tobacco plain packaging and Quitline calls: a population-based, interrupted time-series analysis', The Medical Journal of Australia 200(1): 29-32. 
This text taken from Agenda: A Journal of Policy Analysis and Reform Volume 21, Number 1, 2014, published November 2014 by ANU Press, The Australian National University, Canberra, Australia. 